\title{
Intervención en la presentación del libro "Una muerte anunciada en El Salvador", de Martha Doggett y Pedro Armada*
}

\section{Fernando Alvarez de Miranda, Madrid.}

Invitado por Pedro Amada y Jose María Tojeire, he venido esta tarde aquí no solemente a participar en la presentación de un libro que considero definitivo por sus revelaciones, sino también y sobre todo para hablar de unos amigos. $Y$ de los amigos siempre se habla con pasión. Móxime, cuando se trata, como sucede en este caso, de unos hombres que vivieron apasionadamente día a dfa, arriesgando el corazón y la vida a cada paso.

De la misma forma que en los primeros tiempos del cristianismo, confesar el nombre de Jesucristo llevaba a la muerte, veinte siglos despues, en una sociedad llamada cristiana, fueron llevados a la muerte unos hombres que defendian la verdad del mensaje evangelico. Porque los jesuitas asesinados en El Salvador eran plenamente conscientes del riesgo que significaba su compromiso cristiano. Su compromiso con un pueblo crucificado por el egolsmo y la violencia de los poderosos.

- En 1993, Marthe Doggett, miembro de Lawyers Committee for Human Rights, publico en ingles el libro Death Foretold The Jesuiss Murders in El Salvador. Un efto despues, UCA Editores publicó la traducción espafiola Una muerte anunciada El asesinato de los jesuitas en El Salvador, con la colaboración de Pedro Armada. En 1995, la editorial espaflola PPC publico una nueva edición del libro, ligeramente editada, para el lector espaniol, con un prologo de Jon Sobrino.

El libro fue presentado en Madrid el 5 de diciembre de 1995. En dicho acto hablo don Fernando Alvarez de Miranda, embajedor espafiol en San Salvador durante la década de los ochenta y actualmente Defensor del Pueblo. En su intervención da por sentado la calidad del libro de Martha Doggett y Pedro Armada, "obra maestra", "un libro que considero definitivo", dice en sus palabras iniciales, y con ocasión de la realidad que narra el libro ofrece un testimonio de verdad, solidaridad y esperanza. He aqui sus palabras. 
Como muchos de ustedes saben, las circunstancias de mi vida política me llevaron a El Salvador, al centro del huracán de la lucha de los pueblos americanos por su liberación; a uno de los palses más castigados por la injusticia. Al lugar donde se hizo realidad la terrible afirmación de Ghandi de que "la pobreza es la forma más terrible de violencia".

Alli, como he indicado, conocf a los jesuitas españoles de la UCA; a los mismos que abatió la violencia institucionalizada, fuente de todas las violencias de América Latina. En las largas noches tropicales tuve la oportunidad de compartir sus ilusiones y conocer sus miedos y esperanzas. He dichos muchas veces que aquellas charlas, bajo la luna del trópico, significaron un profundo cambio en mi vida. Porque el ejemplo de aquellos hombres, que dedicaban cada minuto de su existencia a luchar por la liberación de los más pobres, fue para mí una lección decisiva. Por ello, quiero advertir, para que nadie se llame a engaño, que mi intervención aquí esta noche, va a ser apasionada en favor de mis amigos.

En más de una ocasión se ha llamado a los jesuitas de El Salvador, mártires de la paz. Toda su violencia fue la lucha, a veces desesperada y desesperanzada, en favor de los derechos humanos de los más débiles. Y eso fue, precisamente, lo que los llevó a la muerte.

Muchas voces acusadoras han señalado a la teología de la liberación como culpable de defender la violencia en América Latina. Creo que pocas afirmaciones puede haber tan injustas como ésta. La teología de la liberación precisamente ha ayudado a comprender que la violencia más grave, la raíz misma de toda violencia, es la violencia estructural, es decir, la violencia de la civilización de los poderosos que mantiene al tercer mundo $\longrightarrow$ sea, la inmensa mayoría de la humanidad- en condiciones biológicas, sociales, políticas y culturales, absolutamente inhumanas. Esta es la verdadera violencia. Por ello, decir que los teólogos de la liberación defienden la violencia es un error. Porque precisamente ellos han sido quienes más sistemáticamente han denunciado que la violencia estructural -a la cual, por cierto, nadie acusa de violenta, sino simplemente de "reflejo del orden establecido"- es la violencia fundamental contra la que hay que combatir para erradicarla, a ser posible con el mínimo de violencia.

Precisamente el trabajo institucional que desarrollaban los jesuitas en la Universidad Centroamericana, podría resumirse en una lucha continua contra la violencia estructural del país a base de crear las condiciones que permitiesen la liberación de las mayorías populares oprimidas.

Mantener viva esa semilla de liberación fue precisamente lo que les costó la vida a los jesuitas. Pero su muerte no fue inútil. Solía afirmar Monseñor Romero, cada vez que mataban a un sacerdote en El Salvador: "Triste sería que cuando muere tanta gente del pueblo, no matasen a ningún cura". Pues bien, a pesar de la tristeza que nos produjo la muerte de estos curas, es preciso recono- 
cer que el asesinato de los jesuitas sirvió para traer la reconciliación al pueblo salvadoreño. Creo sinceramente que aquellas muertes marcaron el punto de inflexión decisivo para acabar con una guerra entre hermanos que había costado ya 80,000 víctimas. Y para que el propio Estados Unidos, que había contribuido con cinco mil millones de dólares a la financiación de los autores de aquella masacre, reflexionasen sobre el destino de sus inversiones.

En este sentido, el libro de Pedro Armada y Martha Doggett constituye una obra maestra que viene a desvelar el doble juego practicado por el ejército salvadoreño y por el gobiemo de Estados Unidos, que mientras proclamaban su "decidido interés en llegar hasta el fondo del asunto" y en "respetar los derechos humanos", en realidad hizo lo imposible por obstaculizar la investigación del asesinato.

La espeluznante narración de cómo fue entrevistada la testigo del crimen, Lucía Barrera (trasladada a Miami, supuestamente para proteger su seguridad, pero sometida a toda clase de presiones y torturas psicologicas como si fuera una criminal), así como la descripción de cómo fue manipulado el testimonio del mayor Buckland para evitar que trascendiese a la luz pública, son elementos clave para desenmascarar el doble juego de los artífices de la violencia.

Dice Jon Sobrino en la contraportada del libro que "decir la verdad en contra de un mundo de mentira produce una inmensa esperanza". Y creo que esta afirmación es de una importancia decisiva en este mundo, en que nos ha tocado vivir. Nuestra sociedad liene una enorme facilidad para olvidar rápidamente a los santos, colocándolos encima de una peana para que no molesten y para que las cosas puedan seguir igual. Por ello, creo que este libro tiene una importancia decisiva, en cuanto contribuye a denunciar la mentira de los dueños de la sociedad, que no solamente asesinaron a los profetas, sino que trataron de ocultar su crimen mediante una trama de mentiras que les permitiera seguir disfrutando del poder.

Creo que en este sentido es fundamental mantener vivo el recuerdo y el ejemplo de los jesuitas asesinados en El Salvador. Porque ellos entregaron su vida para denunciar el sufrimiento que produce la violencia institucionalizada sobre millares de inocentes. Una violencia injusta y egoísta en favor de unos pocos, que hizo afirmar a los obispos reunidos en Medellín: "No se puede abusar de la paciencia de un pueblo que soporta durante años una condición que difícilmente aceptarían quienes tienen una mayor conciencia de los derechos humanos".

Frente a esa situación establecida por la fuerza, lucharon día a día los jesuitas con las únicas ammas de la denuncia y la verdad. Hasta que hicieron ciertas las palabras de Helder Cámara: "Prefiero mil veces que me maten a tener que matar yo"... 
Esa es la violencia de los pacfficos, la violencia de los justos, la violencia de la paz. Esa es la verdadera violencia de la teología de la liberación. Y esa fue la violencia que practicaron mis amigos los jesuitas: la de entregar su vida por defender la verdad de los pobres. 